\title{
Study on English Learning Motivations Based on the Grey Relation Analysis
}

\author{
Tian Dong, Ya-Ting Tao* \\ School of Foreign Languages, North China Electric Power University, Baoding, 07100, China
}

DOI: $\underline{10.36348 / \text { sijll.2020.v03i09.001 }}$ | Received: 03.09 .2020 | Accepted: 11.09 .2020 | Published: 17.09 .2020

*Corresponding author: Ya-Ting Tao

\section{Abstract}

Based on the Grey Relation Analysis (GRA), this study establishes an evaluation model of motivational factors influencing English learning achievement. Through a questionnaire survey among 266 first-year academic engineering graduate students, this study clarifies the impacts of achievement goal setting and self-efficacy (SE) on English learning achievement (ELA). The results show that: 1) Mastery approach goal, achievement approach goal, English learning behavior self-efficacy, English learning plan self-efficacy and English learning strategy self-efficacy have direct positive influences on English learning achievement, while mastery avoidance goal and performance avoidance goal have direct negative influences on English learning achievement; 2) Mastery approach goal has the biggest impact on self-efficacy, followed by achievement approach goal, English learning plan self-efficacy, English learning strategy self-efficacy, mastery avoidance goal, performance avoidance goal, and performance avoidance goal; 3) On the whole, English learning achievement is related more to achievement goal setting than self-efficacy. This study also demonstrates that compared with traditional evaluation methods of motivational factors, Grey Relation Analysis is superior for its objectivity. The results of the present study can give some hints on English teaching.

Keywords: achievement goal setting; self-efficacy; English learning achievement; Grey Relation Analysis.

Copyright @ 2020: This is an open-access article distributed under the terms of the Creative Commons Attribution license which permits unrestricted use, distribution, and reproduction in any medium for non-commercial use (NonCommercial, or CC-BY-NC) provided the original author and source are credited.

\section{INTRODUCTION}

Among all individual factors influencing second language acquisition, English learning motivation is always regarded as one of the most dynamic one, and also one of the most important affective one which influences English learning achievement. In fields of psychology and linguistics, scholars have achieved consensus on the main motivation factors including cognitive emotion, achievement goal setting, attribution, self-efficacy, persistent and learning objectives [1]. All these factors could possess, to some extent, certain predicative power on English learning achievements. Therefore, how to predicate English achievements by these factors scientifically has always been a research focus.

As extremely special and important elements of motivation, self-efficacy and achievement goal setting, however, haven't received adequate scholarly attention until recent years. In 1995, based on their own previous English learning motivation model, Gardner et al took self-efficacy and achievement goal setting into account. A review of the related literature shows that recent studies in linguistics mainly focus on the relationship between two variables, for example, correlation analysis of goal setting and English learning achievement [2], correlation and regression analysis of self-efficacy and English learning achievement [3], and path analysis of self-efficacy and goal setting [4]. These methods, however, are all based on a large amount of data which follows a normal distribution. Furthermore, self-efficacy and goal setting, complex dynamic systems, must change with one's cognition. Obviously, traditional multivariate statistical methods could hardly meet our requirements. The Grey Relation Analysis can avoid the inherent defects of multivariate statistical methods. Moreover, it only needs a limited amount of data to estimate the behavior of an uncertain system. Grey system originated from Control Science and Engineering. In the objective world, grey information (semi-definite information) dominates our life rather than white information (given information) and black information (unknown information). Grey means the ambiguity of the information here. The rational behind grey system is exploring unknown information by given information, namely, whitening information, which will be conductive to illuminating system operating law [5]. After about 20 years of development, grey system has 
developed a great many analytical methods like grey prediction, grey decision making, grey control and GRA, just to name a few. GRA is regarded as the most efficient and widely used one among them. It is a new multivariate analytical method for investigating the similarity between two variables based on the changing geometrical shapes of reference sequence and comparartive sequence. The greater the similarity of shapes, the higher the correlation. As GRA is based on the changing trend, there are no restrictions on the amount of data and distribution law. At the same vein, it could examine the dynamic correlation between two variables. Hence, GRA should be given priority when it comes to incomplete information and data. It now has been widely used in science and social science.

Selecting 266 first-year academic engineering graduate students from a National Key Universities in Hebei province as the subjects, this study, therefore, takes the initiative to establish a model to examine the complex relations among achievement goal setting, self-efficacy and English learning achievement by GRA and thus guiding graduate students to set accurate English learning goals and enhancing their self-efficacy and ability.

\section{RESERACH BACKGROUNDS Achievement goal setting}

Pintrich [6] conceptualized achievement goal setting as an individual's general schema or theory for approaching the task, doing the task and evaluating their performance on the task. It is also a construct reflecting one's task choices, self-set goals, ability and effort mechanisms in learning and performance. The classifications of achievement goal setting have gone through three different stages, namely, dichotomous framework [7], trichotomous framework [8] and fourfactors framework [6]. Now, four-factors framework has been widely accepted in that it's reasonable both in terms of theory and statistical significance [8]. The four-factors framework including mastery approach goal, mastery avoidance goal, performance approach goal and performance avoidance goal, therefore, will be adopted in this study. Learners with mastery approach goal focus on mastering concepts and developing skills, while those with mastery avoidance goal are in attempt to avoid losing the exiting skill and knowledge or failing to accomplish the task. For individuals with performance approach goal, they are eager to

$$
\begin{aligned}
& \mathrm{Y}=\{\mathrm{Y}(\mathrm{k}) \mid \mathrm{k}=1,2,3, \ldots, \mathrm{n}\} \\
& X_{i}=\left\{X_{i}(K)=1,2,3, \ldots, n\right\}
\end{aligned}
$$

Given that the physical interpretations of variables within the system are different; the dimensions of indicators are different, which easily demonstrate their capabilities and receive positive feedback, while those with performance avoidance goal are concerned with hiding their lack of knowledge or ability and afraid of failure [8]. Mainly based on the framework of dichotomy and trichotomy, previous studies about achievement goal setting fail to take the influence of mastery avoidance goal into account. It is generally acknowledged that learners with mastery approach goal could get higher achievements and mastery approach goal also could affect scores by adjusting learning strategies in an indirect way. Learners with mastery avoidance goal and performance avoidance goal will get lower achievements. For the relations between performance approach goal and learning achievement, researchers have different views where some thought they positively correlate with each other while others argued they negatively correlate.

\section{Self-efficacy}

Self-efficacy is defined as people's judgment or predication of their capabilities to execute and accomplish a specific type of performance [9]. It is, actually, derived from Bandura's reciprocal determination theory [9], which places great emphasis on the interactions among person, environment and behavior. Considering the English learning characteristics in the information age, [10] proposed self-efficacy includes three dimensions: English learning behavior self-efficacy (LBSE), English learning strategy self-efficacy (LSSE) and English learning plan self-efficacy (LPSE). But there is no consensus on the relations between self-efficacy and English learning achievement. Some researchers held the view that there is significant positive correlation between them [1], while others argued that no significant correlation between them and at last, she found self-efficacy could affect English learning achievement in an indirect way by path analysis. Surprisingly, Wang Tianfa et al. [11] even proposed the relation of these two variables is dialectical, hence, mutually prediction.

\section{GREY RELATION ANALYSIS}

Definition 1 Reference sequences are data sequences reflecting the system's behavior characteristics; Comparative sequences are data sequences composed by variables influencing system's behavior. The reference sequence and comparative sequences are as follow:

leads to incomparability or false results. Therefore, the indicators should be transformed into dimensionless form [4]. The present study uses extreme method: 


$$
\text { Let } \begin{aligned}
& x_{i}^{\prime}=\frac{x_{i}-m}{M-m}(i=1,2 \ldots 266 ; j=1,2,3,4) \\
& \text { Where } \underbrace{\mathrm{Max}}_{=1 \leqq i \leq 266}\left\{\mathrm{x}_{\mathrm{i}}\right\}, \\
& \mathrm{m}=\underbrace{\min }_{1 \leq i \leq 266}\left\{\mathrm{X}_{\mathrm{i}}\right\}, x_{j}^{\prime} \in[0,1], \\
& X_{i}^{\prime}=\left\{X_{(K)}^{\prime} \mid K=1,2,3, \ldots n\right\} \text { is the comparative sequences after dimensionless methods. }
\end{aligned}
$$

Definition 2 Correlation coefficient between reference sequences and comparative $x_{i}^{\prime}=\frac{x_{i}-m}{M-m}(i=1,2 \ldots 266 ; j=1,2,3,4)$ sequences:

$$
\eta_{i}(k)=\frac{\min _{i} \min _{k}\left|y(k)-x_{i}^{\prime}(k)\right|+\rho \max _{i} \max _{k}\left|y(k)-x_{i}^{\prime}(k)\right|}{\left|y(k)-x_{i}^{\prime}(k)\right|+\rho \max _{i} \max _{k}\left|y(k)-x_{i}^{\prime}(k)\right|}
$$

Where $\left|\mathrm{y}(\mathrm{k})-\mathrm{x}^{\prime}(\mathrm{k})\right|$ is the absolute error between $\mathrm{y}(\mathrm{k})$ and $\mathrm{x}^{\prime}(\mathrm{k})$ on the $\mathrm{k}$ point:

$\min _{i} \min _{k}\left|y(k)-X^{\prime}{ }_{i}(K)\right|$ is the smallest value; $\rho$ is the resolution ratio $(0<\rho<1) ; \rho=0.5$ in this study.

Grey relation grade is as follow:

$$
r_{i}=\frac{1}{n} \sum_{1}^{n} \eta_{i}(k), k=1,2,3, \ldots, n
$$

\section{English learning research based on Grey Relation Analysis}

The core of GRA is to calculate the correlation degree among variables and put it in numerical order. Generally speaking, the greater similarity the changing trends of two variables, the higher the correlation degree. Compared with traditional multivariate statistics (correlation analysis, regression analysis, etc), GRA has no restrictions on the amount of data and distribution law. It, therefore, has widely applied to many fields like Education [12], Management [13] and Environment [14]. Language teaching practice is also one of them [12]. Developed a formative assessment framework for oral English on the basis of GRA. Other scholars [15] proposed a predicative model of English writing performance by combining GRA and BP neural network [16]. Investigated the relation among listening vocabulary, metacognitive consciousness and listening comprehension of medical majors based on GRA. Admittedly, these studies all have some implications on English teaching. Nevertheless, few studies focused on the impacts of self-efficacy and achievement goal setting on English learning achievements in the field of language teaching by GRA. Furthermore, there is no consensus on the relations among AGS, SE and ELA. More importantly, it is of great significance of building a predicative model of ELA for AGA and SE. Selecting 266 first-year academic engineering graduate students from a National Key Universities in Hebei province as the subjects, this study, therefore, aims to establish a scientifically predicative model of ELA for AGA and SE based on the four-factors framework of AGA and trichotomous framework of SE with the another purpose of clarifying the relation between motivational variables and ELA by combining quantitative and qualitative methods.

\section{METHODS Participants}

This study selected 266 first-year academic engineering graduate students from a National Key Universities in Hebei province, which are from 10 majors including Electric Engineering, Electric science and Technology, Environmental Science and Engineering and Mechanical engineering, etc. Their ages random from 21 to $28(\mathrm{M}=23) .197$ students are male $(69.4 \%)$, and 79 are female $(30.6 \%)$. Their average score for the National Entrance Examination of English for Postgraduates is 62.97. Here, we use the following table (table 1) to present it more intuitively. 
Table-1: Descriptive statistics of Participants

\begin{tabular}{|c|c|c|c|}
\hline & & Numbers & Percentage \\
\hline \multirow{5}{*}{} & Electric engineering & 62 & $24.0 \%$ \\
\cline { 2 - 4 } & Electronic Science and Technology & 7 & $2.7 \%$ \\
\cline { 2 - 4 } & Power Engineering and Engineering Therm physics & 44 & $17.1 \%$ \\
\cline { 2 - 4 } & Heating, Gas Supply, Ventilating and Air & 10 & $3.9 \%$ \\
\cline { 2 - 4 } & Conditioning Engineering & 9 & $3.5 \%$ \\
\cline { 2 - 4 } & Chemical Engineering and Technology & 22 & $8.5 \%$ \\
\cline { 2 - 4 } & Environmental Science and Engineering & 30 & $11.6 \%$ \\
\cline { 2 - 4 } & Mechanical Engineering & 22 & $8.5 \%$ \\
\cline { 2 - 4 } & Control Science and Engineering & 30 & $11.6 \%$ \\
\cline { 2 - 4 } & Information and Communication Technology & 22 & $8.5 \%$ \\
\cline { 2 - 4 } & Automation & 258 & $100.0 \%$ \\
\hline \multirow{5}{*}{ Gender } & Total & 79 & $69.4 \%$ \\
\cline { 2 - 4 } & Male & 258 & $30.6 \%$ \\
\cline { 2 - 4 } & Female & $790.0 \%$ \\
\hline
\end{tabular}

\section{Instruments}

The required data were collected through a questionnaire which is composed of three parts. The first part is about the basic information of the participants like age, gender and majors. The second and third parts are used to survey self-efficacy and achievement goal setting of students by scales developed by experts respectively. A pilot study was launched before a large-scale test in order to determine the final questionnaire. And the final questionnaire was filled out in some classes about 10 minutes in October 2019 and then collected immediately. Students were all informed of the objective of the study and the time needed to fill in it prior to distributing the questionnaires. The effective returns-ratio is $97 \%$ with 258 valid questionnaires of 266 . The author tested the reliability and validity of the questionnaire using spss 25.0. The results showed that: Cronbach $=0.899$, $\mathrm{KMO}=0.866, \mathrm{p}=0.000$, which proves factor analysis could be made and the reliability of the questionnaire is comparatively high.

\section{ANALYSIS PROCEDURES \\ Defining reference sequence and comparative sequence}

The motivational factors influencing English learning achievement can be regarded as a grey system in that it's quite difficult to identify the relations among these factors and the impacts of these factors on English learning achievement. Based on previous research, this study takes four dimensions of the achievement goal setting (mastery approach goal, mastery avoidance goal, performance approach goal and performance avoidance goal) and three dimensions of self-efficacy (English learning plan, English learning behavior and English learning strategy) as comparative sequences $\left(X_{i}(k)\right)$, English learning achievement as reference sequences $(\mathrm{Y}) . X_{1}(k), X_{2}(k), X_{3}(k), X_{4}(k), X_{5}(k), X_{6}(k), X_{7}(k)$ denote mastery approach goal, mastery avoidance goal, performance approach goal and performance avoidance goal, English learning plan self-efficacy, English learning behavior self-efficacy and English learning strategy self-efficacy respectively.

\section{Normalizing the raw data}

The extreme method is adopted for normalizing the raw data in the present study to satisfy non-dimension, scaling, and polarization conditions before the comparability of the sequences. (see formula $3)$.

\section{Calculating correlation coefficients}

Correlation coefficients can be calculated based on formula (4).

\section{Calculating the grey relation grade}

Grey relation grade can be calculated according to formula 5 after getting correlation coefficients. Taking mastery approach goal--English learning achievement as an example:

Comparative sequence: $X_{1}(k)=(0.67,0.33, \ldots 1)$

Reference sequence: $Y(k)=(0.57,0.63, \ldots .0 .9)$

Substituting the sequences into formula (4) and (5):

$$
\begin{gathered}
\eta_{1}(\mathrm{k})=(0.76,0.51,0.49, \ldots 0.76) \\
r_{1}=\frac{1}{258} \sum_{1}^{258} \eta_{1} \mathrm{~K}=\frac{1}{258} * 189.79=0.74
\end{gathered}
$$

In the same way, the other grey relation degree can be calculated

$$
r_{2}=0.67, r_{3}=0.73, r_{4}=0.64, r_{5}=0.69, r_{6}=0.62, r_{7}=0.69
$$




\section{Ranking grey relation grade}

According to the results calculated above, grey relation grades between 7 English learning motivational factors and English learning achievement are ranked as following:

$$
r_{1}>r_{3}>r_{5}=r_{7}>r_{2}>r_{4}>r_{6}
$$

Therefore, mastery approach goal has the strongest impact on English learning achievement, followed by performance approach achievement, then, learning plan self-efficacy and learning strategy self-

Definition 1 Let a sequence be as follow:

$$
X=(x(1), x(2), \ldots, x(n))
$$

Then, $\alpha=x(k)-x(k-1), k=2,3, \ldots, n$ is the slope of $X$ in $[k-1, k]$.

Let $Y_{i}$ and $X_{i}$ be the reference sequence and comparative sequence respectively, and they have the same length:

$$
\begin{aligned}
& \mathrm{Y}=(y(1), y(2), \ldots, y(n)) \\
& X_{i}=\left(x_{i}(1), x_{i}(2), \ldots, x_{i}(n)\right),(n=1,2, \ldots, 7)
\end{aligned}
$$

The slope of $\mathrm{X}_{\mathrm{i}}$ and $\mathrm{Y}_{\mathrm{i}}$ in $[\mathrm{k}-1, \mathrm{k}],(\mathrm{k}=2,3, \ldots, \mathrm{n})$ can be denoted as follow:

$$
\begin{aligned}
K_{y} & =\left(K_{y 1}, K_{y 2}, \ldots, K_{y(n-1)}\right) \\
K_{x} & =\left(K_{x 1}, K_{x 2}, \ldots, K_{x(n-1)}\right)
\end{aligned}
$$

Let $\mathrm{K}_{\mathrm{yx}}=\left(\mathrm{K}_{\mathrm{y} 1} / \mathrm{K}_{\mathrm{x} 1}, \mathrm{k}_{\mathrm{y} 2} / \mathrm{K}_{\mathrm{x} 2}, \ldots, \mathrm{K}_{\mathrm{y}(\mathrm{n}-1)} / \mathrm{K}_{\mathrm{x}(\mathrm{n}-1)}\right)$ denote the sequences of the ratio of the slope of $Y_{i}$ and $X_{i}^{\prime}$ in all time points.

$$
\overline{K_{y x}}=\frac{1}{n-1} \sum_{i=1}^{n-1}\left(k_{y i} / k_{x i}\right)
$$

If $\overline{K_{y x}}>0$, then the reference sequence positively correlates with comparative sequence, or vice versa. Taking mastery approach goal--English learning achievement as an example:

Reference sequence: $Y=(0.57,0.63, \ldots, 0.9)$

Comparative sequence: $X_{1}=(0.76,0.60, \ldots, 1.0)$

Substituting the above sequences into formula (2):

$$
\begin{gathered}
\alpha_{1}=0.63-0.57=0.06, \beta_{1}=0.60-0.76=-0.16 \\
\alpha_{2}=0.51-0.63=-0.12, \beta_{2}=0.53-0.60=-0.07 \\
\alpha_{n-1}=0.9-0.71=0.19, \beta_{n-1}=1-1=0
\end{gathered}
$$

Substituting $\alpha$ and $\beta$ into formula (3):

$$
\begin{gathered}
k_{y x_{1}}=(-.16 / 0.06,-0.07 /-0.12, \ldots, 0 / 0.19)=(-0.56,1.19,2.54,2.08, \ldots, 0) \\
\overline{k_{y x_{1}}}=\frac{1}{n-1} \sum_{j-1}^{n-1}\left(\alpha_{j} / \beta_{j}\right)=0.3023,(n=258)
\end{gathered}
$$

Thus, mastery approach goal positively correlates English learning achievement. In the same way, we could judge the other correlations. The results are presented in the following table (table 2) intuitively: 
Table-2: Results of grey relation grade

\begin{tabular}{|c|c|}
\hline Variables & grade \\
\hline MAG1 & 0.74 \\
\hline PAG1 & 0.73 \\
\hline LSSE & 0.69 \\
\hline LPSE & 0.69 \\
\hline MAG2 & -0.67 \\
\hline PAG2 & -0.64 \\
\hline LBSE & 0.62 \\
\hline
\end{tabular}

(Note: PAG1:Performance approach goal; PAG2: Performance avoidance goal; MAG1: Mastery approach goal; MAG2: Mastery avoidance goal; LSSE: Learning strategy self-efficacy; LPSE: Learning plan self-efficacy; LBSE: Learning behavior self-efficacy.)

\section{RESULTS AND DISCUSSION}

From table 2, it can be seen that 7 motivational factors all have significant impacts on English learning achievement. Among them, mastery approach goal, performance approach goal, English learning behavior self-efficacy, English learning plan self-efficacy and English learning strategy self-efficacy positively correlate with English learning achievement respectively, while the rest factors negatively correlate with English learning achievement. In terms of positive correlations, mastery approach goal has the most significant impact on English learning achievement (0.74), followed by performance approach goal (0.73), English learning plan self-efficacy (0.69) and English learning strategy self-efficacy (0.69) and English learning behavior self-efficacy (0.62). As for negative correlation, the impact of mastery avoidance goal on English learning achievement (-.67) is stronger than this of performance avoidance goal (-0.64). Generally speaking, the impact of goal setting is more significant than this of self-efficacy. Therefore, we may draw the conclusion that the appropriate goal setting is critical for English learning achievement in the process of learning English. At the same time, the efficient English learning plan, strategy and behavior also facilitate the improvement of English learning achievement.

Under the hint of this study, we hope teachers could lead graduate students to set appropriate goals and stick to them during the courses of academic English teaching. Specifically, teachers should: 1) enable students to be clear about their own English achievement goals according to long-term goals; 2) guide students to the positive attribution in order to improve their self-confidence; 3) encourage them to handle the difficulties during English learning process.

\section{CONCLUSION}

Through questionnaires and Grey Relation Analysis, this study discussed the impacts of achievement goal setting and self-efficacy on English learning achievement of engineering graduate students. The grey relation model put forward in the present study clarifies the grade and negativeness or positiveness of relations between motivational factors and English learning achievement by combining qualitative and quantitative analyses. The model has been proved to be feasible and efficient to overcome the limitations in the previous studies. Furthermore, our study provides a new perspective to the future studies which try to analyze the dynamic correlations of motivational factors based on small samples. Some limitations still exist, though we are quite prudent and careful during the study process. Future study should: 1) expand their scope of study; 2) taking more motivational factors into consideration; 3) Pay attention to the interaction within the motivational factors.

\section{REFERENCES}

1. Qin, X., \& Wen, Q. (2002). Motivational Structures of Non-English Majors. Foreign Language Teaching and Research, 46, 51-58.

2. Zhang, W., \& Yuan, L. (2004). The Effects of achievement goals on Non-English Majors' English Learning. Technology enhanced foreign language education, 9, 21-25.

3. Dai, Y. (2010). The Correlational Study of College EFL Students' Goal Orientations (Master's thesis). Available from China master's this full-text database.

4. Orientation, A. G., \& Ability, A. E. L. (2014). The Mediating Role of Self-efficacy [J]. Foreign Languages in China, 3.

5. DENG, J.L. (1996). Basic methods of grey system. Wuhan, China: Technology Press of Huazhong University.

6. Pintrich, P. R., \& De Groot, E. V. (1990). Motivational and self-regulated learning components of classroom academic performance. Journal of educational psychology, 82(1), 33.

7. Ames, C. (1992). Classrooms: Goals, Structures, and Student Motivation. Journal of Educational Psychology, 84, 261-271.

8. Elliot, A. J., \& Mcgregor, H. A., Gable, S. (1999). Achievement goals, study strategies, and exam performance: A mediational analysis. Journal of Educational Psychology, 91, 549-563.

9. Bandura, A. (1986). Social foundations of thought and action : a social cognitive theory. Journal of applied psychology, 12, 169.

10. Liang, H., \& Chen, M. (2018). Questionnaire Compilation for College Students' English Learning Self-efficacy. Journal of Ningbo University (Educational Science Edition), 40, 2227.

11. Wang, T. F., Yang, J. Y., Wang, Y., \& Zhang, H. (2007). College Students' English-Learning SelfEfficacy: Components and Causes. Shandong Foreign Language Teaching Journal, 3.

12. Lee, Y. J. J., \& Lan, L. W. (2014). Application of grey relational analysis to expose individual student's cognitive difficulties in English public speaking: A formative assessment 
framework. Grey Systems: Theory and Application, 4(2), 232-249.

13. Huang, J., Dang, Y., Wang, J., \& Xue, Q. (2020). Novel Deng's Grey Development Relation Model Based on Information Difference and Its Application in Sanatorium Performance Evaluation. Mathematical Problems in Engineering, 2020.

14. Li, W., Ye, Y., Hu, N., Wang, X., \& Wang, Q. (2019). Real-time warning and risk assessment of tailings dam disaster status based on dynamic hierarchy-grey relation analysis. Complexity, 2019.

15. Hu, S., Gu, Y., \& Jiang, H. (2016). Writing Score
Prediction Model Based on Grey Relation Analysis and Neural Network [J]. Control theory and applications, 35, 6-9.

16. Li, H., Liu, X., Hu, F. (2020). Study on the relationship among listening vocabulary, metacognitive awareness, and listening comprehension among Medical undergraduates based on grey correlation analysis $[\mathrm{J}]$. Medical Education Research and Practice, 28, 136-139.

17. Cao, M.X. (2008). Study and improvement on properties of positive and negative of grey incidence degree model. Systems Engineering and Electronics, 1086-1088. 